Arq. Bras. Med. Vet. Zootec., v.69, n.2, p.483-490, 2017

\title{
Fontes de contaminação de Yersinia enterocolitica durante a produção de leite
}

\author{
[Contamination sources of Yersinia enterocolitica during milk production] \\ A.B. Tavares, A.I.A. Souza, C.F. Dulac, L.M. Moreira, L. Dominguez, \\ H.L. Gonzalez, N.D. Cereser, C.D. Timm \\ Universidade Federal de Pelotas - Pelotas, RS
}

\begin{abstract}
RESUMO
Objetivou-se determinar as possíveis fontes de contaminação de Yersinia enterocolitica em diferentes pontos do processo de ordenha de vacas leiteiras em oito propriedades da região de Pelotas, RS, ao longo de um ano. Foram analisadas amostras de leite cru de conjunto logo após a ordenha, água de estábulo leiteiro, mão de ordenhador, balde de recolhimento do leite e insuflador de teteiras. As amostras de leite cru e água foram coletadas em frascos estéreis, e as amostras de mão, balde e teteiras com zaragatoas estéreis. As amostras de leite cru foram submetidas a um pré-enriquecimento em água peptonada, sendo posteriormente incubadas em caldo PSTA, adicionado de ampicilina. As amostras de água foram filtradas em membrana de éster de celulose e incubadas em caldo TSB. As amostras de leite após incubação em PSTA, as membranas utilizadas na filtragem da água incubadas em TSB, bem como o material de mãos, balde e teteiras coletadas nas zaragatoas, foram semeados em ágar MacConkey e incubados para a obtenção de colônias. Colônias características foram analisadas por meio de duplex PCR para confirmação da espécie. Os perfis moleculares dos isolados de Y. enterocolitica foram comparados utilizando-se a técnica de rep-PCR. Y. enterocolitica foi isolada de 9,37\% das amostras de leite, $6,25 \%$ das amostras de água e $12,5 \%$ das amostras de mão. Não houve similaridade no perfil de bandas dos isolados encontrados, entretanto foi identificada a presença de cepas diferentes na mesma amostra, demonstrando uma variedade grande de cepas distribuídas no ambiente. A presença de Y. enterocolitica em leite cru no Brasil é preocupante, já que uma quantidade considerável do produto ainda é comercializada de forma clandestina, expondo o consumidor ao risco de infecção pela bactéria, ao consumi-lo sem tratamento térmico adequado.
\end{abstract}

Palavras-chave: ordenha, leite, água, mão, gastroenterite

\begin{abstract}
This work was performed in order to determine the possible Yersinia enterocolitica contamination sources at different points of the dairy cows milking process in eight properties of Pelotas, RS, in a year. Raw milk samples were analyzed immediately after milking, as well as water from milking parlor, milkers' hands, milk collection bucket, and inflator liners. The samples of raw milk and water were collected in sterile bottles and hand samples, and sterile swabs were used for the buckets and liners. The raw milk samples were subjected to a pre-enrichment peptone water buffered and subsequently incubated in PSTA broth with added ampicillin. Water samples were filtered through cellulose ester membrane and incubated in TSB medium. The milk samples after incubation in PSTA, the membranes used in water filtration were incubated in TSB and the material of the hands material, bucket and liners collected in the swabs were plated on MacConkey agar to obtain colonies. Characteristics of colonies were analyzed by duplex PCR to confirm the species. The molecular profiles of Y. enterocolitica isolates were compared using rep-PCR. Y. enterocolitica was isolated from 9,37\% of milk samples, 6,25\% of water samples and $12,5 \%$ of hand samples. There weren't similarities in the band profile of the isolates found; however, the
\end{abstract}

Recebido em 4 de maio de 2015

Aceito em 9 de setembro de 2016

E-mail: alana_btavares@yahoo.com.br 
presence of different strains was found in the same sample, demonstrating a variety of strains distributed in the environment. The presence of Y. enterocolitica in raw milk in Brazil is dangerous, considering that the product is sold clandestinely, exposing consumers to the risk of infection by the bacterium, when consuming it without proper heat treatment.

Keywords: milking, milk, water, hand, gastroenteritis

\section{INTRODUÇÃO}

O leite é um alimento essencial para a população, estando a sua qualidade relacionada aos cuidados higiênico-sanitários durante a produção, quando pode ser contaminado por micro-organismos indesejáveis, como Yersinia enterocolitica, que é uma bactéria patogênica transmitida ao homem por meio do consumo de alimentos contaminados (Franco e Landgraf, 2003)

Apesar de a legislação brasileira não exigir a pesquisa de $Y$. enterocolitica em água e alimentos, diferentes autores têm relatado a ocorrência dessa bactéria em leite e derivados (Yucel e Ulusoy, 2006; Hanifian e Kani, 2012; Najdenski et al., 2012), sendo frequentemente a colonização bacteriana do trato intestinal dos bovinos a origem da contaminação (Ruegg, 2003). A água também é uma importante fonte de contaminação e disseminação dessa bactéria. Cepas de $Y$. enterocolitica com potencial patogênico já foram isoladas de água sem tratamento (Iwata et al., 2005) e também de água potável (Pandove et al., 2012), ratificando a sua importância como fonte de transmissão da bactéria.

A doença causada por $Y$. enterocolitica, caracterizada por gastroenterite, é considerada a terceira zoonose mais notificada na Europa (European..., 2012). É estimado que 116.716 pessoas sejam infectadas anualmente por $Y$. enterocolitica nos EUA (Scallan et al., 2011), demonstrando ser essa bactéria uma importante causa de doenças transmitidas por alimentos (DTA). Em países em desenvolvimento, é rara a existência de vigilância epidemiológica de casos de yersiniose, já que muitas vezes o diagnóstico não revela o causador da gastroenterite.

Surtos relacionados à ingestão de leite e derivados inadequadamente pasteurizados demonstram o perigo potencial que o leite pode representar como fonte de contaminação de $Y$. enterocolitica para os humanos (Longenberger et al., 2014). Essa bactéria tem capacidade de sobreviver a baixas temperaturas (Hanna et al., 1977), tornando o risco ainda maior, já que a refrigeração é muito utilizada como método de conservação de produtos lácteos e é considerada muitas vezes segura. Fatores relacionados à higiene dos equipamentos de ordenha, do ambiente e dos manipuladores podem levar à contaminação do leite, elevando o risco de ocorrência de DTA. Consequentemente, a manutenção da segurança dos alimentos deve ser garantida durante todo o processo de produção, em que a obtenção do leite deve ser um ponto gerador de contaminação a ser considerado (Ruegg, 2003).

Considerando a hipótese de que a água utilizada para limpeza de equipamentos, as mãos dos ordenhadores, o balde utilizado para recolhimento do leite ordenhado $\mathrm{e}$ os insufladores das teteiras possam ser fontes de contaminação de $Y$. enterocolitica para o leite, o presente trabalho teve como objetivo determinar as possíveis fontes de contaminação de $Y$. enterocolitica durante a obtenção do leite em propriedades rurais.

\section{MATERIAL E METODOS}

Foram realizadas coletas em oito propriedades, localizadas na região de Pelotas, Rio Grande do Sul, com sistema de ordenha sem canalização e com tanques resfriadores próprios. Foram obtidas amostras de três pontos do fluxograma de ordenha, balde, insuflador de teteira e mão de ordenhador, bem como da água utilizada durante o processo e de leite de conjunto obtido logo após o término da ordenha.

Durante um ano, foram feitas quatro coletas de três em três meses (setembro e dezembro de 2013 e março e junho de 2014) em cada propriedade, gerando um total de 160 amostras analisadas. 
As amostras de água foram coletadas com cuidados de assepsia, impedindo o contato do frasco coletor estéril com a torneira, diretamente destas, localizadas no interior do estabelecimento, após escoamento durante três minutos, em volume de aproximadamente 400mL (Apha, 2001).

As amostras representativas das mãos dos manipuladores, dos equipamentos e dos utensílios foram coletadas com o auxílio de zaragatoas estéreis. As amostras de superfície dos baldes foram coletadas mediante a fricção da zaragatoa em uma área de $100 \mathrm{~cm}^{2}$ delimitada por meio de gabarito de aço inoxidável (Apha, 2001). Os insufladores foram coletados antes do início da ordenha, friccionando-se as zaragatoas em movimentos circulares na porção final de cada um (McDonald et al., 1993). No caso das amostras de mão dos ordenhadores, a zaragatoa foi friccionada em movimentos giratórios da parte inferior da palma direita, até a extremidade dos dedos, repetindo-se esse procedimento três vezes na direção de cada dedo ; já nas bordas, foi passada a zaragatoa em movimentos de vaivém, avançando em um dos lados da mão onde a linha do punho se inicia, passando entre os dedos e, ao final, do outro lado da mão até o punho (Apha, 2001). Após a obtenção das amostras, as zaragatoas foram mergulhadas em quatro mililitros de água peptonada a $0,1 \%$. As amostras de leite cru, em volume de $200 \mathrm{~mL}$, foram coletadas com o auxílio de uma concha estéril diretamente do balde que recebe o leite ordenhado e acondicionadas em frasco estéril (Brito et al., 1998).

Logo após as coletas, as amostras foram transportadas ao laboratório em caixa isotérmica contendo gelo reciclável.

Para a obtenção dos isolados, o material das zaragatoas foi semeado diretamente por esgotamento em ágar MacConkey (Kasvi, Itália) e incubado a $30^{\circ} \mathrm{C}$ por $24 \mathrm{~h}$.

As amostras de água foram processadas segundo as recomendações da U.S. Food and Drug Administration - FDA (Weagant e Feng, 2007) para obtenção de colônias isoladas, conforme descrito a seguir. As amostras foram filtradas em membrana de éster de celulose de $47 \mathrm{~mm}$ de diâmetro e poros $0,45 \mu$ (Compendium..., 2001), as quais foram depositadas em frascos tipo
Erlenmeyer contendo $100 \mathrm{~mL}$ de caldo tripticase de soja (TSB,Acumedia, EUA) e incubadas a $30^{\circ} \mathrm{C}$ durante 24h. Após o enriquecimento, foi feita semeadura em ágar MacConkey e incubação a $30^{\circ} \mathrm{C}$ durante $24 \mathrm{~h}$.

Quanto às amostras leite, $25 \mathrm{~mL}$ foram adicionados a $225 \mathrm{~mL}$ de água peptonada tamponada (APT, Isofar, Brasil) para préenriquecimento por 30 dias a $4^{\circ} \mathrm{C}$. Após, $1 \mathrm{~mL}$ do pré-enriquecimento foi adicionado em $100 \mathrm{~mL}$ de caldo peptona sacarose Tris azida de sódio ampicilina (PSTA), composto por $1 \mathrm{~g}$ de peptona A (Acumedia), $1 \mathrm{~g}$ de sacarose (Synth, Brasil), $3 \mathrm{~g}$ de Tris hidroximetil aminometano (Ludwig Biotec, Brasil), 0,0125g de verde brilhante (Synth), 0,192g de azida de sódio (Synth) e água destilada qsp 1L, suplementado com ampicilina (Sigma Aldrich, EUA) na concentração de $5 \mathrm{mg} / \mathrm{L}$ e incubado a $28^{\circ} \mathrm{C}$ durante $48 \mathrm{~h}$ (Vidon e Delmas, 1981). Após o enriquecimento, foi feita semeadura em ágar MacConkey e incubação a $30^{\circ} \mathrm{C}$ durante $24 \mathrm{~h}$.

Três colônias lactose negativas de cada amostra obtidas por meio da semeadura em MacConkey foram semeadas em infusão de cérebro e coração (BHI, Acumedia) e, após incubação a $30^{\circ} \mathrm{C}$ por $24 \mathrm{~h}$, foram misturadas com $20 \%$ de glicerol, para manutenção de estoque a $-70^{\circ} \mathrm{C}$.

O DNA dos isolados suspeitos de $Y$. enterocolitica foi extraído conforme Sambrook e Russel (2001). Resumidamente, o pellet obtido por centrifugação de $1 \mathrm{~mL}$ de cultura em caldo BHI foi ressuspendido em $100 \mu \mathrm{L}$ de tampão STES [Tris- $\mathrm{HCl}$ 0,2M, $\mathrm{NaCl} 0,5 \mathrm{M}$, SDS 0,1\% $(\mathrm{m} / \mathrm{v})$, EDTA 0,01M, pH 7,6]. Foram adicionados $50 \mu \mathrm{L}$ de pérolas de vidro e $100 \mu \mathrm{L}$ de fenol/clorofórmio. Após homogeneização por $1 \mathrm{~min}$, a mistura foi centrifugada a $13.000 \mathrm{~g}$ por $5 \mathrm{~min}$. O sobrenadante foi coletado e precipitado em dois volumes de etanol absoluto e 0,1 volume de $\mathrm{NaCl} 5 \mathrm{M}$ a $-70^{\circ} \mathrm{C}$ por $30 \mathrm{~min}$. Uma nova centrifugação foi realizada a $13.000 \mathrm{~g}$ por $20 \mathrm{~min}$, o sobrenadante foi descartado e o pellet lavado com etanol a $70 \%$. Após eluição em $40 \mu \mathrm{L}$ de tampão de eluição (Tris-HCl 10mM, EDTA $1 \mathrm{mM}, \mathrm{pH} 7,4)$, foi adicionado $1 \mu \mathrm{L}$ de RNAse $(10 \mu \mathrm{g} / \mu \mathrm{L})$. O DNA extraído foi estocado a $70^{\circ} \mathrm{C}$.

Foi realizada a técnica de reação em cadeia da polimerase para identificação 
de $Y$. enterocolitica, conforme Neubauer et al. (2000), usando-se os primers Y1 (AATACCGCATAACGTCTTC) e Y2 (CTTCTTCTGCGAGTAACGTC). Cada $25 \mu \mathrm{L}$ da mistura de reação continha os primers específicos para o gene rRNA 16S na concentração de $10 \mathrm{ng} ; 2,5 \mu \mathrm{L}$ mix dNTP $10 \mathrm{x}$; 0,5U de Taq DNA polimerase; 5x de tampão; $0,5 \mu \mathrm{L}$ de DNA. A amplificação foi realizada em termociclador TC-3000 (Techne, Staffordshire, UK) a $94^{\circ} \mathrm{C}$ durante $10 \mathrm{~min}$, seguida por 30 ciclos de $94^{\circ} \mathrm{C}$ durante $1 \mathrm{~min}, 68^{\circ} \mathrm{C}$ por $25 \mathrm{~s}$ e $72^{\circ} \mathrm{C}$ por 30 s. Uma extensão final foi realizada a $72^{\circ} \mathrm{C}$ durante $10 \mathrm{~min}$. Os produtos de PCR, corados com GelRed ${ }^{\mathrm{TM}}$ (Uniscience, São Paulo, Brasil), foram visualizados em gel de agarose 1,5\% (Panreac Química SA, Barcelona, Espanha), utilizando-se L-PIX 112 EX (Loccus biotecnologia, Cotia, São Paulo, Brasil). Como controle positivo, foi utilizada $Y$. enterocolitica ATCC 9610.

Os isolados de $Y$. enterocolitica foram agrupados por meio da técnica de reação em cadeia da polimerase com elemento repetitivo palindrômico (rep-PCR), fazendo uso do primer $(\mathrm{GTG})_{5}$ (Versalovic et al., 1991). As condições da rep-PCR foram as seguintes: $2,5 \mu \mathrm{L}$ de DNA, $2 \mu \mathrm{L}$ do oligonucleotídeo 5'GTGGTGGTGGTGGTG-3', 12,5 $\mu \mathrm{L}$ de Master Mix (Qiagen, Alemanha) e $8 \mu \mathrm{L}$ de água para completar o volume da reação. Para a amplificação, foram realizados 1 ciclo de $94^{\circ} \mathrm{C}$ por $5 \mathrm{~min}, 30$ ciclos subsequentes de $95^{\circ} \mathrm{C}$ por $30 \mathrm{~s}, 45^{\circ} \mathrm{C}$ por $1 \mathrm{~min}$ e $60^{\circ} \mathrm{C}$ por $5 \mathrm{~min}$, e finalmente 1 ciclo de $60^{\circ} \mathrm{C}$ por 16 min. Para a visualização dos padrões de banda das diferentes regiões amplificadas, os produtos da rep-PCR foram corados com GelRed e a eletroforese foi realizada em gel de agarose $2 \%$.

Os perfis de bandas obtidos foram analisados segundo Tenover et al. (1995), cuja classificação se dá em quatro formas: indistinguíveis (nenhuma banda diferente), intimamente relacionadas (2-3 bandas distintas), possivelmente relacionadas (4-6 bandas distintas) e diferentes (mais de 7 bandas distintas).

\section{RESULTADOS E DISCUSSÃO}

Y. enterocolitica foi isolada da água utilizada no estábulo leiteiro, das mãos dos ordenhadores e de leite cru imediatamente após a ordenha (Tab. 1).

Tabela 1. Fontes de isolamento de Y. enterocolitica no período de setembro de 2013 a junho de 2014

\begin{tabular}{llllll}
\hline \multirow{2}{*}{$\begin{array}{l}\text { Propriedades } \\
\text { rurais }\end{array}$} & \multicolumn{5}{c}{ Amostras } \\
\cline { 2 - 5 } A & Leite* & Água & Mãos & Balde & Teteira \\
B & ---- & +--- & +--- & ---- \\
C & ---- & ---- & ---- & ---- & --- \\
D & ---- & ---- & ---+ & ---- & ---- \\
E & +--- & ---- & ---+ & ---- & --- \\
F & ---- & ---- & --+- & ---- & --- \\
G & ---+ & ---+ & ---- & ---- & ---- \\
H & ---+ & ---- & ---- & ---- & ----
\end{tabular}

*Nas colunas onde aparecem quatro símbolos (+ ou -), cada um corresponde a uma coleta. A ordem das coletas é a mesma em toda linha. Ausência de Y. enterocolitica (-); presença de Y. enterocolitica (+).

Das amostras de leite analisadas, 9,37\% (3/32) foram positivas para $Y$. enterocolitica. Esse resultado é semelhante ao encontrado em um estudo realizado no Irã (Hanifian e Kani, 2012), no qual foi revelada a presença da espécie em 7,62\% (27/354) das amostras de leite cru, e menor que o encontrado por Yucel e Ulusoy
(2006), em um estudo na Turquia, no qual foi identificada a presença de $Y$. enterocolitica em $25 \%(25 / 100)$ das amostras. Nesses dois países, bem como no Brasil, é comum o consumo de leite cru nas propriedades rurais e a produção de derivados de forma artesanal (Yucel e Ulusoy, 2006; Hanifian e Kani, 2012). Embora no Brasil 
a comercialização de leite cru diretamente ao consumidor seja proibida pelo Decreto-Lei $\mathrm{n}^{\circ}$ 923, de 10 de outubro de 1969 (Brasil, 1969), esse alimento, em muitos casos, é vendido clandestinamente, expondo o consumidor ao risco de contrair patógenos que tal produto possa estar veiculando (Abrahão et al., 2005).

No Brasil, anteriormente, já houve relato de isolamento de $Y$. enterocolitica em leite cru no estado do Rio de Janeiro (Tibana et al., 1987). $\mathrm{Na}$ ocasião, a frequência de isolamento foi de $32,4 \%$, nível considerado alto em comparação com outro trabalho realizado no estado de São Paulo (Tassinari et al., 1994), no qual a frequência de isolamento de $Y$. enterocolitica em leite cru foi de $19,4 \%$, valor elevado em relação ao encontrado nesta pesquisa. Entre os anos de 1980 e 1990, o Centro Nacional de Referência em Y. enterocolitica fez 468 isolamentos do gênero Yersinia em alimentos, 46 amostras continham $Y$. enterocolitica, sendo 12 de leite cru (Falcão, 1991). Os resultados do presente estudo mostram que o problema ainda persiste, chamando a atenção para o risco a que está exposto o consumir desse produto sem tratamento térmico. $\mathrm{O}$ fato de ter sido isolada $Y$. enterocolitica em três das oito $(37,5 \%)$ propriedades rurais que fizeram parte do estudo é um dado ainda mais preocupante, pois mostra que leite contaminado com $Y$. enterocolitica é produzido em um percentual elevado de estabelecimentos. Por outro lado, essa contaminação parece não ser persistente dentro da propriedade, uma vez que não houve isolamento do leite em mais de uma coleta na mesma propriedade.

A água é considerada uma das principais fontes de contaminação e disseminação de patógenos, principalmente quando não é submetida a tratamento adequado. Neste trabalho, foi possível isolar $Y$. enterocolitica de $6,25 \%(2 / 32)$ das amostras de água de $25 \%$ (2/8) das propriedades. Entretanto, não foi encontrada $Y$. enterocolitica no leite desses estabelecimentos, parecendo não haver uma relação entre a contaminação da água e do leite. Por outro lado, a presença de $Y$. enterocolitica na água das propriedades estudadas é preocupante, já que essa água é utilizada pelos ordenhadores para limpeza de equipamentos e também para higiene pessoal. Como agravante, foi observado durante a pesquisa que nenhuma das propriedades fazia algum tipo de tratamento da água, como recomenda a Instrução Normativa 51 do Ministério da Agricultura, de 18 de setembro de 2002 (Brasil, 2002), que estabelece que a água destinada à produção de leite deve estar dentro de padrões de qualidade adequados.

Também foi possível isolar a bactéria de 12,5\% (4/32) das amostras das mãos dos ordenhadores. Apesar de os ordenhadores não manipularem diretamente o leite, eles são a principal ligação entre equipamentos, utensílios, animais e o leite, podendo concorrer para a transferência de contaminação entre esses. Embora outros microorganismos já tenham sido pesquisados em mãos de ordenhadores, além do presente trabalho, não existem estudos na região envolvendo a bactéria em questão e esse possível ponto de contaminação.

Já foram pesquisadas outras espécies bacterianas durante a ordenha e os autores consideraram que o manipulador pode ser o responsável pela disseminação de patógenos para outras etapas do processamento e, consequentemente, para o leite (Kagkli et al., 2007; Olivindo et al., 2009). Portanto, é de suma importância que seja realizada a antissepsia adequada das mãos, antes e durante a ordenha, especialmente nas propriedades leiteiras da região, de característica familiar, onde foi observado que a mesma pessoa manipula os animais e os equipamentos.

Embora Y. enterocolitica não tenha sido isolada de amostras de balde e teteiras, a correta higienização dos equipamentos com produtos adequados e água de qualidade segue sendo imprescindível para a obtenção de um leite seguro.

Não houve reincidência no isolamento da bactéria nas coletas seguintes nos mesmos pontos, parecendo que a contaminação é bastante variável ou que é facilmente eliminada. Nas propriedades A e F, foi possível isolar $Y$. enterocolitica de amostras diferentes durante a mesma coleta (1YAA1, 1YAM1 e 4YFA1, 4YFL2, 4YFL4), no entanto a rep-PCR não revelou similaridade entre os isolados (Fig. 1), o que sugere que as fontes de contaminação podem ser constituídas por pontos diversos e que várias formas de disseminação da bactéria podem estar envolvidas. 


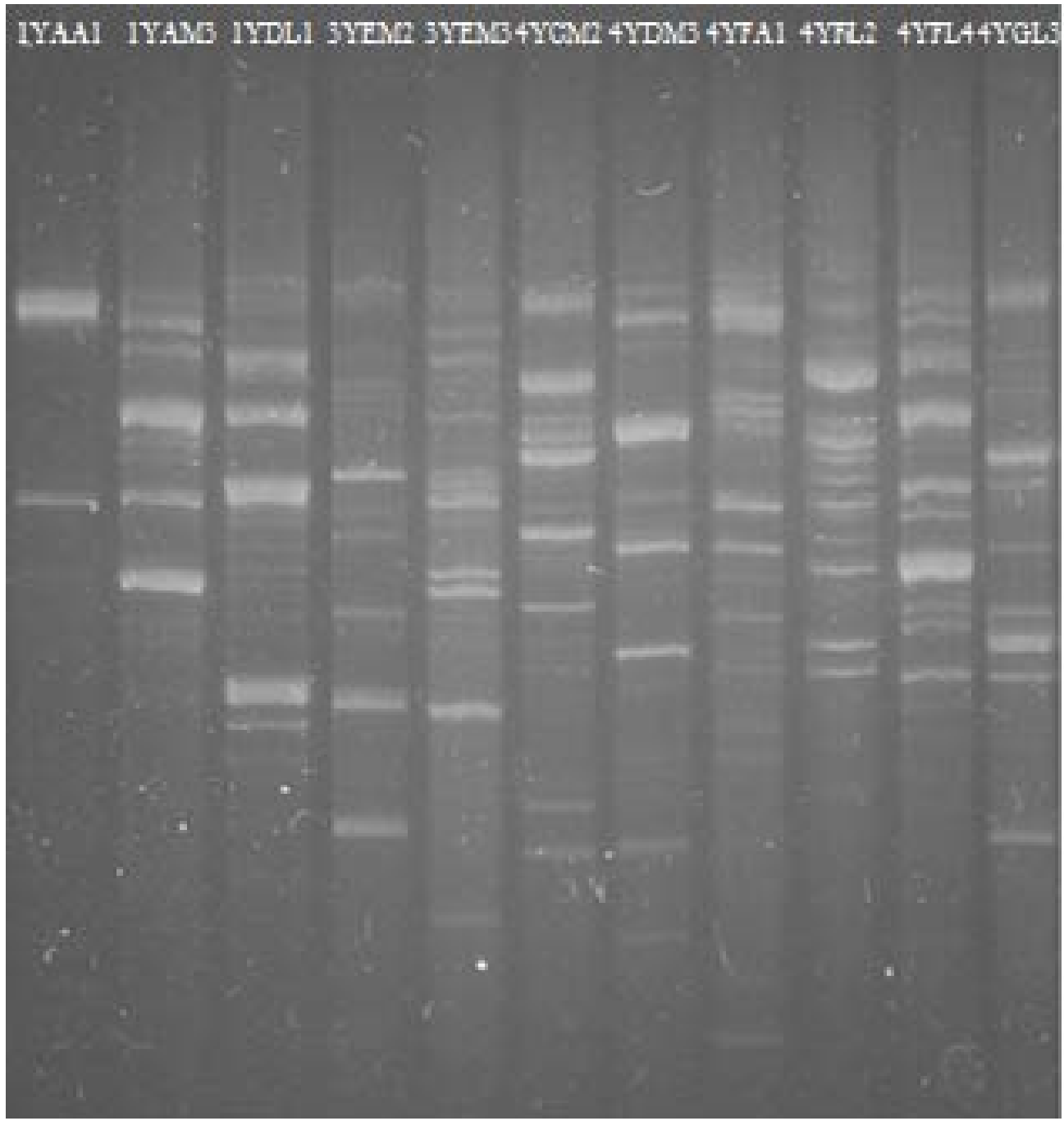

Figura 1. Eletroforese em gel de agarose dos produtos da rep-PCR. As inscrições nas extremidades superiores das colunas correspondem aos isolados. 1YAA1: $1^{\text {a }}$ coleta, propriedade A, amostra de água; 1YAM3: $1^{\text {a }}$ coleta, propriedade A, amostra de mão; 1YDL1: $1^{\text {a }}$ coleta, propriedade D, amostra de leite; 3YEM2 e 3YEM3: $3^{\text {a }}$ coleta, propriedade E, amostras de mão; 4YFA1: $4^{\text {a }}$ coleta, propriedade F, amostra de água; 4YFL2 e 4YFL4: 4ª coleta, propriedade F, amostras de leite; 4YGL1: $4^{\mathrm{a}}$ coleta, propriedade G, amostra de leite.

A variedade de perfis moleculares observados na rep-PCR representa a diversidade de cepas existentes nas amostras analisadas. Corroborando esse fato, uma amostra de mão de ordenhador (propriedade E) e uma amostra de leite (propriedade F) apresentaram, cada uma, dois isolados com perfis de bandas diferentes entre si (3YEM2 e 3YEM3; 4YFL2 e 4YFL4), demostrando a ocorrência de cepas distintas, simultaneamente, na mesma amostra.

A presença de $Y$. enterocolitica no leite revela que há falhas no processo de obtenção do produto e, embora a origem da contaminação do leite não tenha sido determinada pela rep-PCR, a bactéria foi isolada da água utilizada na ordenha e das mãos dos ordenhadores, dois pontos fundamentais para o controle higiênico-sanitário. Cuidados especiais devem ser dirigidos à qualidade da água utilizada no estábulo leiteiro, pois ela entra em contato com os equipamentos que recebem o leite podendo contaminá-lo, e à higiene das mãos dos ordenhadores, que é quem tem contato com todas as etapas do processo nesse tipo de atividade, podendo ser disseminador de patógenos para o leite cru. 


\section{CONCLUSÃO}

Y. enterocolitica foi isolada de leite cru, indicando que o leite produzido no Sul do Brasil pode estar contaminado por essa bactéria. Embora ocorra de forma esporádica, um percentual preocupante de propriedades ocasionalmente produz leite cru contaminado pela bactéria, o que indica negligência em relação aos cuidados relativos ao controle de $Y$. enterocolitica nos estabelecimentos leiteiros. Y. enterocolitica também foi isolada da água utilizada na ordenha e das mãos de ordenhadores, podendo estes servir como fontes de contaminação para o leite.

\section{REFERÊNCIAS}

ABRAHÃO, R.M.C.M.; NOGUEIRA, P.A.; MALUCELLI, M.I.C. O comércio clandestino de carne e leite no Brasil e o risco da transmissão da tuberculose bovina e de outras doenças ao homem: um problema de saúde pública. Arch. Vet. Sci., v.10, p.1-17, 2005.

BRASIL. Ministério da Agricultura, Secretaria de Inspeção de Produto Animal. Instrução Normativa n.51, de 18 de setembro de 2002. Regulamentos técnicos de produção, identidade, qualidade, coleta e transporte de leite. Brasília: [MAPA], 2002. 39p.

BRASIL. Os Ministros da Marinha de Guerra, do Exército e da Aeronáutica Militar. Decreto-lei ${ }^{\circ}$ 923, de 10 de outubro de 1969 . Fica proibida a venda de leite cru, para consumo direto da população, em todo o território nacional. Diário Oficial da União. 13 out. 1969. Seção 1. p.8601.

BRITO, M.A.V.P.; BRITO, J.R.F.; SOUZA, H.M.; VARGAS, O.L. Avaliação da sensibilidade da cultura de leite do tanque para isolamento de agentes contagiosos da mastite bovina. Pesqui. Vet. Bras., v.18, p.39-44, 1998.

COMPENDIUM of methods for the microbiological examination of foods, 4.ed. Washington: APHA, 2001. p.676.

EUROPEAN Food Safety Authority, European Centre for Disease Prevention and Control. The European Union summary report on trends and sources of zoonoses, zoonotic agents and foodborne outbreaks in 2010. v.10, 2012. 442p.
FALCÃO, D.P. Occurrence of Yersinia spp. in foods in Brazil. Int. J. Food Microbiol., v.14, p.179-182, 1991.

FRANCO, B.D.G.M.; LANDGRAF, M. Microorganismos patogênicos de importância em alimentos. In: FRANCO, B.D.G.M.; LANDGRAF, M. Microbiologia dos alimentos. Rio de Janeiro: Atheneu, 2003. p.33-81.

HANIFIAN, S.; KHANI, S. Prevalence of virulent Yersinia enterocolitica in bulk raw milk and retail cheese in northern-west of Iran. Int. J. Food Microbiol., v.155, p.89-92, 2012.

HANNA, M.O.; STEWART, C.; CARPENTER, L. ANDERZANT, C. Effect of heating, freezing and $\mathrm{pH}$ on Yersinia enterocolitica-like organisms from meat. J. Food Prot., v.40, p.689-692, 1977.

IWATA, T.; UNE, Y.; OKATANI, A.T. et al. Yersinia enterocolitica serovar O:8 infection in breeding monkeys in Japan. Microbiol. Immunol., v.49, p.1-7, 2005.

KAGKLI, D.M.; VANCANNEYT, M.; HILL, C. et al. Enterococcus and Lactobacillus contamination of raw milk in a farm dairy environment. Int. J. Food Microbiol., v.114, p.243-251, 2007.

LONGENBERGER, A.H.; GRONOSTAJ, M.P.; YEE, G.Y. et al. Yersinia enterocolitica infections associated with improperly pasteurized milk products: southwest Pennsylvania, MarchAugust 2011. Epidemiol. Infect., v.142, p.16401650, 2014.

McDONALD, J.S.; KINSER, M.L.; ADAMS, D.S. Studying the effects of backflushing milking units. Vet. Med., v.88, p.382-386, 1993.

NAJDENSKI, H.; HEYNDRICKX, M.; HERMAN, L. et al. Quantification of Yersinia enterocolitica in raw milk using qPCR. Vet. Microbiol., v.160, p.428-434, 2012.

NEUBAUER, H.; HENSEL, A.; ALEKSIC, S.; MEYER, H. Identification of Yersinia enterocolitica with in the Genus Yersinia. Syst. Appl. Microbiol., v.23, p.58-62, 2000.

OLIVINDO, C.S.; CHAPAVAL, L.; VILLARROEL, A.B.S. et al. Detecção de Staphylococcus aureus utilizando a técnica de REP-PCR no monitoramento da qualidade do leite de cabra. Rev. Bras. Zootec., v.38, p.13171321, 2009. 
PANDOVE, G.; SAHOTA, P.; VERMA, S.K. et al. Epidemiology, virulence and public health significance of Yersinia enterocolitica in drinking water. Afr. J. Microbiol. Res., v.6, p.5905-5913, 2012.

RUEGG, P.L. Practical food safety interventions for dairy production. J. Dairy Sci., v.86, Suppl., p.E1-E9, 2003.

SAMBROOK, J.; RUSSELL, D.W.; Molecular cloning: a laboratory manual.New York: Cold Spring Harbor Laboratory Press, 2001. v.2, [34p].

SCALLAN, E.; HOEKSTRA, R.M.; ÂNGULO, F.J. et al. Foodborne illness acquired in the United States - major pathogens. Emerg. Infect. Dis., v.17, p.7-15, 2011.

TASSINARI, A.R.; FRANCO, B.D.G.M.; LANDGRAF, M. Incidence of Yersinia spp. in food in São Paulo, Brazil. Int. J. Food Microbiol., v.21, p.263-270, 1994.

TENOVER, F.C.; ARBEIT, R.D.; GOERING, R.V. et al. Interpreting chromosomal DNA restriction patterns produced by pulsed-field gel electrophoresis: criteria for bacterial strain typing. J. Clin. Microbiol., v.33, p.2233-2239, 1995.
TIBANA, A.; WARNKEN, M.B.; NUNES, M.P. et al. Ocurrence of Yersinia species in raw and pasteurized milk in Rio de Janeiro, Brazil. J. Food Protec., v.50, p.580-583, 1987.

VERSALOVIC, J.T.; KOEUTH, T.; LUPSKI, J.R. Distribution of repetitive DNA sequences in eubacteria and application to fingerprinting of bacterial genomes. Nucl. Acids Res., v.19, p.6823-6831, 1991.

VIDON, D.J.; DELMAS, C.L. Incidence of Yersinia enterocolitica in raw milk in Eastern France. Appl. Environ. Microbiol., v.41, p.355$359,1981$.

WEAGANT, S.D.; FENG, P. Yersinia enterocolitica. In:__ Bacteriological analytical manual. Chapter 8, 2007. Available in:

$<$ http://www.fda.gov/Food/FoodScienceResearch /LaboratoryMethods/ucm072633.htm> Accessed in: 20 Mar. 2015.

YUCEL, N.; ULUSOY, H.A. Turkey survey of hygiene indicator bacteria and Yersinia enterocolitica in raw milk and cheese samples. Food Control, v.17, p.383-388, 2006. 